hollow, and incessant, repeated every five or six seconds during sleep at night as well as during the day. The violence was such that it threatened to "tear her chest in pieces." Her friends wondered how any frame could withstand so constant and terrible an agitation. Yot there was no fever, the chest exhibited nothing but the ordinary râles of what was in those days called "dry bronchitis," and the loss of flesh was by no means commensurate with the apparent gravity of the condition. This unfortunate girl was bled, leeched, blistered, and antimonialised without the slightest relief. She then had antispasmodics galore but with no effect. Next every species of narcotic was administered without the very faintest benefit. Then, fortunately, her physicians discontinued their visit and the case was taken up by an old retainer in the family. This old woman suggested a full dose of turpentine with castor oil for the relief of colic. In two or three hours a large mass of tapeworm was passed and every symptom disappeared. Robert J. Graves was the soul of sincerity. How ferw men would have had the courage to narrate such a failure as occurring in their own practice. What a lesson in frankness and humility! In treating any cough how needful it is to remember that we can cough from irritation of any portion of the body supplied by the great rago-sympathetic ; and what part of the body is not supplied by this most important group of nerves?

How many ceruminous coughs have been treated without an examination of the auditory meatus? At p. 32 of my small work on Eczema I have described a persistent dermatitis of the navel in a child which resisted months of treatment and was then suddenly cured by santonin given to expel a round worm.

I am, Sirs, yours faithfully,

Edward Blake, M.D. Aberd., \&c.

Seymour-street, W., Jan. 28th, 1905.

\section{MOSQUITOES AND MALARIAL FEVER.} To the Editors of THE LANCET.

SIRS,-Not seeing the subject mentioned in THE LANCET I forward to you an extract from the Times of Feb. 8th which is not without general interest. It is from "our own correspondent," Colombo, and is as follows:- "Sir H. A. Blake, Governor of Ceylon, announced at a meeting of the Asiatic Society that Sinhalese books of the sixth century described 67 varieties of mosquitoes and 424 kinds of malarial fever caused by mosquitoes."

Putting aside the question of numbers the association of these insects in causation in days long gone past is a matter which seems worthy of notice in present medical literature and the record of it may lead some of those who may have the opportunity to dip more into the subject as detailed in these old books.-I am, Sirs, yours faithfully,

Lee, S.E., Feb. 13th, 1905 .

FRANCIS H. WELCH, F.R.C.S. Eng.

\section{MANCHESTER. \\ (From OUR OWN CoRrespondent.)}

Ancoats Hospital.

A CASE of death from blood poisoning occurred at the Ancoats Hospital on Jan. 18th and at the inquest some strictures were passed on the system in vogue for treating slight cases of accident. A young married mill-hand on Dec. 23rd scratched her hand in the mill. Next day she had pain and was taken to the hospital where she was attended to by a nurse and told to come next morning. However, she eventually died with all the symptoms of general blood poisoning on Jan. 18th. The resident house physician, Dr. F. G. Hack, said it was the custom for the nurses to treat trivial cases of accident without consulting the medical officer. The two medical men present could not deal with all the cases. They had 100 beds upstairs to look after. A verdict of "Accidental death" was returned. The jury did not attach blame to anyone but expressed the opinion that every accident should be seen by a qualified medical man. Dr. Hack promised to convey the recommendation to the governing body. In this case the pain in the arm and other symptoms might have led a medical man to take a more serious view of the matter than that taken by the nurse and the confidence of the public generally would no doubt be lowered if it came to be understood that accidents apparently slight but susceptible of fatal developments would probably bo seen by a nurse only.
Degrees in Dentistry.

At a meeting of the court of the University of Manchester held on Jan. 18th Professor W. Stirling, in accordance with the recommendation of the board of faculty, moved the adoption of proposed ordinances for degrees and diplomas in dentistry. The Manchester Dental School was founded in 1885 and there are now about 40 students. These students pass the same matriculation as others and before they obtain a licence to practise have to study for four years. Special attention has to be given to dental anatomy and physiology, human and comparative. They go through the same attendance on surgery and pathology as required for the medical students and must have a year's attendance at a general hospital for clinical surgery. The student has to learn the mechanical part of his art at a dental hospital. It was proposed to institute degrees in dentistry of Bachelor of Dental Surgery and Master of Dental Surgery. In this Manchester is not alone, Trinity College, Dublin, and the University of Birmingham already giving dental degrees while Liverpool proposes to do so The motion, which was seconded by Dr. J. Dreschfeld, was carried and it was resolved that the adoption of the ordinances should be communicated to the Universities of Liverpool and Leeds and to the General Medical Council.

\section{Manchester Royal Infirmary.}

The annual meeting of the trustees of the Manchester Royal Infirmary was held on Feb. 10th. Mr. Cobbett, the chairman of the board of management, gave some interesting information as to the progress being made towards the erection of the new infirmary at Stanley-grove. The ground was cleared, sewerage and drainage work had been executed, so that now the surface was ready for the commencement of the laying of the foundations. There is still some anxiety among a section of the supporters of the infirmary as to the central receiving house. It was decided some time since that there should be no beds but the fear seems to be that so much may be expended at Stanley-grove that there may be no funds available for the receiving house even without beds. The chairman was able, however, to remove that impression. Two gentlemen resigned the membership of the board because they could not share in the financial responsibility for the scheme which they consider too costly. One of them, moreover, gave as an additional reason a supposed change in the character of the institution, that "it will become much more a teaching hospital instead of the primary one for the treatment of the sick poor." (The construction here seems to present some difficulty.) "Placed there the professional influence will increase and the lay share in the management must decrease," a state of things to which he objects. It seems a curious idea, and one that could only occur to a layman, that there is any antagonism between the treatment of a patient where it is carried out under the quick, intelligent eyes of students of medicine and that given where there are none to observe and none to criticise-the only difference at all likely to occur being, perhaps, that in the former case it will be more thorough and more carefully carried out than in the latter. If this change is objected to the strong man would retain his post in order that he could oppose the change and not retire on the mere rumour that such a change may be impending. Manchester is a great medical centre and the teaching and education of the next generation of practitioners is surely as important a work in relation to the welfare of the people as any that can occupy the best energies of the wisest and most benevolent among us. There is plenty of room for the coöperation of lay and professional helpers. For many years past they have worked cordially together, to the great advantage of the community, and there is no reason to fear that their relations will be less useful and agreeable in the future.

The Hospital for Śkin Diseases.

The new hospital in Quay-street, adjoining the old one, is approaching completion and it is expected that the whole scheme may be completed next year. An appeal for funds has brought in nearly $£ 31,000$ but $£ 5000$ more are required. Of the 57,159 attendances during the year 22,665 were made by "light" patients. Dr. R. B. Wild said the results of the special "light" treatment were highly satisfactory. The $x$ rays, the Finsen, and the Finsen-Reyn lamps had been chiefly used. Radium had not fulfilled the high expectations of a year ago but this was thought to be "largely due to the fact that the amount of radium available was sufficient to treat only such small areas of disease that they could be treated more effectively by other methods." 